Revista do SELL

v. 6 , no. 3

ISSN: $1983-3873$

\title{
PRODUÇÃO DO GÊNERO SINOPSE DE LIVRO E REVISÃO TEXTUAL: COAUTORIA OU INTERVENÇÃO NO TEXTO DE OUTREM?
}

\author{
PRODUCTION OF THE GENRE BOOK SYNOPSIS AND TEXTUAL REVISION: CO-
} AUTHORSHIP OR INTERVENTION IN THE TEXT OF OTHERS?

\author{
Patrícia Souza Lemos \\ Universidade Estadual do Sudoeste da Bahia \\ Marcia Helena de Melo Pereira \\ Universidade Estadual do Sudoeste da Bahia
}

\begin{abstract}
RESUMO: Neste trabalho, investigamos a produção do gênero sinopse de livro e sua revisão textual, levando em consideração o processo de construção que, neste caso, engloba a escrita do livro e sua posterior revisão, com vistas à publicação e que, portanto, passa pelas etapas do trabalho editorial. Consideramos a revisão uma etapa da produção textual, que contribui para a melhoria do texto em aspectos linguístico-gramaticais e produção de sentido. O revisor intervém no texto e produz alguns trechos, e é essa sua 'entrada' no texto-sinopse que desperta nosso interesse sobre a possibilidade de coautoria, em termos linguístico-discursivos. Teoricamente, tomamos por base autores como Bakhtin (2011), Oliveira (2016), Foucault (2002) e Possenti (2002), abordando conceitos como autoria, gêneros discursivos, revisão textual. Para tanto, selecionamos uma sinopse de obra literária, apresentando quatro versões: a primeira, produzida pelo autor do livro; a segunda, revisada pelo profissional; a terceira, 'melhorada' pelo revisor, ou seja, com entrada maior na escrita; e, a quarta, a versão final. Acreditamos que as intervenções do revisor contribuíram para deixar o texto mais claro e até mais literário e informativo a respeito da obra, o que nos permite dizer que, além de realizar um trabalho técnico, o revisor tornou-se, também, coautor.
\end{abstract}

PALAVRAS-CHAVE: Gênero sinopse; Revisão textual; Coautoria.

ABSTRACT: In this work, we investigate the production of the genre book synopsis and it textual revision, regarding the construction process that encompasses the writing of the book and it further revision, with a view to publication and that, therefore, passes through editorial work stages. We consider the revision a stage of the textual production, which contribute to the textual improvement considering grammatical-linguistics aspects and meaning production. The reviewer implements interventions in the text and produces some excerpts, and that is his 'entrance' in the synopsis-text that awakens our interest about the co-authorship possibility, in linguistic-discursive terms. Theoretically, we based on authors such as Bakhtin (2011), Oliveira (2016), Foucault (2002) and Possenti (2002), addressing issues like authorship, discursive genres, textual revision. Therefore, we select a synopsis of literary work, presenting four versions: the first, produced by the book's author; the second, revised by the professional; the third, 'upgraded' by the reviewer, with a larger entrance at writing; and, fourth, the final version. We believe that the reviewer's interventions improve the clarity text and give it more literary and informative regarding the book, which allows us to say that, besides making a technical work, the reviewer become, also, co-authorship.

KEYWORDS: Synopsis genre; Textual revision; Co-authorship. 


\section{Revista do SELL \\ v. 6 , no. 3 \\ ISSN: $1983-3873$}

\section{INTRODUÇÃO}

A concepção de autoria vem sofrendo transformações ao longo do tempo (TARGINO, 2005). Nessa perspectiva, podemos citar as contribuições de autores ${ }^{1}$ (termo utilizado correntemente) como Bakhtin, Barthes, Foucault, Possenti, entre outros, cada um a seu tempo, fornecendo-nos as bases para nossas reflexões. Dessa forma, podemos mencionar discussões a respeito de um autor-criador (BAKHTIN, 2011), da morte do autor (BARTHES, 1984), de uma função autor (FOUCAULT, 2002), de indícios de autoria (POSSENTI, 2001; 2002) - discussões que nos permitem refletir a respeito da figura autoral, além de servirem de base para a discussão que aqui se apresenta: a possibilidade não apenas de autoria na produção de um texto-sinopse de livro ficcional, mas, principalmente, a possibilidade de coautoria, como um processo instaurado na etapa de revisão textual - caracterizado por intervenções em um texto.

Conforme destaca Targino (2005), a coautoria não é uma novidade, visto que pode ser observada em vários momentos do desenvolvimento das sociedades, especialmente relacionada às descobertas técnico-científicas e, mais recentemente, ligada à produção acadêmico-científica, com vistas à publicação. Mas, antes de abordarmos a noção de coautoria, sua ocorrência ou não, é necessário discutir sobre a autoria, para, primeiramente, verificar a presença de autoria em uma sinopse de livro de literatura ficcional e, depois, verificar a possibilidade de coautoria, no processo de revisão, sendo o revisor coautor juntamente com o produtor da versão inicial do texto e do livro. Essa é nossa intenção. Para tanto, consideramos que, no processo de produção textual realizado em dupla ou em grupo, um dos escreventes quase sempre se sobressai em relação ao(s) outro(s), aquele que dá o "pontapé inicial", considerando a participação efetiva do(s) outro(s) na produção (TARGINO, 2005).

Passarelli (2012), no livro Ensino e correção na produção de textos escolares, tratando do processo da escrita, seu ensino e como compreendê-la, apresenta o testemunho de José Roberto Torero, autor de Terra Papagalli, juntamente com Marcus Aurelius Pimenta, dando testemunho de que a narrativa produzida por eles contou, ainda, com treze revisões conjuntas. Nas palavras de Torero:

\footnotetext{
1 O termo 'autor' (autores), neste caso, está sendo usado da forma como se utiliza correntemente nos textos acadêmico-científicos para se referir aos produtores dos textos teóricos que fundamentam uma pesquisa.
} 


\section{Revista do SELL}

v. 6 , no. 3

ISSN: $1983-3873$

- Nosso método, quando a gente trabalha em dupla, é que um de nós faz a primeira versão, geralmente o Marcus faz toda uma primeira versão. Eu pego o que ele fez, refaço tudo de novo, até o fim, reescrevo. Aí, ele pega... e reescreve. E nisso a gente vai conversando muito. [...] a gente faz algumas versões conjuntas [...] aí vai lendo em conjunto [...] (PASSARELLI, 2012, p. 152).

O evento de escrita, mencionado acima, assemelha-se à produção da sinopse sob análise, aqui, ou seja, houve uma produção inicial por um dos escreventes, seguida de reformulações, ajustes, revisão, enfim, pelo segundo escrevente, o revisor; além disso, ocorreu, mesmo que de forma interativa, por E-mail e mensagem instantânea em redes sociais, alguma conversa a respeito do texto, de sua construção².

Quanto à revisão textual, destacamos que não se trata apenas de correção gramatical, mas uma etapa da produção escrita (OLIVEIRA, 2016), que permite tornar o texto claro, objetivo, legível, apresentável a um público, contribuindo não só para sua apresentação formal, mas, também, para a construção de sentido(s) - objetivo efetivo do locutor/enunciador. Desse modo, em relação ao texto-sinopse em questão, visto representar uma espécie de texto 'oficial' para apresentação da obra, destaca-se que foi submetido à revisão, assim como o próprio livro, a fim de ser publicado, sendo a revisão, portanto, uma das etapas do serviço editorial (YAMAZAKI, 2009), essencial para dirimir possíveis desvios de linguagem. Portanto, investigamos a possibilidade de coautoria entre autor e revisor, nessa etapa da produção do texto - a revisão -, uma vez que o revisor promove mudanças significativas no texto do autor (escrevente inicial).

Assim, apresentamos, nas seções seguintes, considerações a respeito do gênero sinopse, o contexto de sua produção/revisão, a discussão sobre autoria, revisão e coautoria e, por fim, nossas análises.

\section{O GÊNERO SINOPSE DE LIVRO}

Abordar a noção de gênero textual - que, de acordo com Marcuschi (2008), não é novidade, mas está na moda - não significa simplesmente descrever um gênero em

\footnotetext{
2 Está sendo desenvolvida na Universidade Estadual do Sudoeste da Bahia (UESB/2017) uma dissertação de mestrado sobre escrita conjunta que procura verificar o comportamento de duas duplas de estudantes universitários escrevendo uma resenha conjuntamente, no intuito de investigar a influência do outro na produção escrita e se um dos escreventes se sobressai em relação ao outro. O corpus é formado por dados processuais (gravação em áudio da conversa mantida pela dupla, duas versões do texto e entrevista posterior com as duplas). O trabalho é de autoria de Anne Carolline Dias Rocha Prado, sob orientação da Prof. ${ }^{a}$ Dr. ${ }^{a}$ Márcia Helena de Melo Pereira.
} 


\section{Revista do SELL}

v. 6 , no. 3

ISSN: $1983-3873$

termos de características que diferenciam uns dos outros, e, sim, abordar a comunicação humana: uma atividade complexa. Conforme Bakhtin (2011), o uso da linguagem está relacionado a todas as esferas de atividade do homem. Além disso, esse uso se efetiva mediante enunciados, compreendidos, na perspectiva bakhtiniana, como o ato de enunciar, de produzir discurso, seja oral ou escrito (BAKHTIN, 2011).

Sendo assim, cada esfera de "utilização da língua elabora seus tipos relativamente estáveis de enunciados [...] os gêneros do discurso" (BAKHTIN, 2011, p. 262), que "refletem condições específicas e as finalidades de cada referido campo" (p. 261) por meio de seus três pilares: o conteúdo, o estilo e a estrutura composicional. De acordo com Bakhtin, quanto aos gêneros orais e escritos, podemos classificá-los como primários e secundários, respectivamente; dessa maneira, os gêneros secundários, escritos, considerados complexos, têm origem com base nos gêneros orais, do cotidiano.

Silva e Gomes (2011), com base no Dicionário de Gêneros Textuais, de Sérgio Roberto Costa, apresentam o relato de uma atividade escolar, sendo esta o desenvolvimento de sequência didática com o gênero textual resumo/sinopse de filme. Os autores caracterizam resumo e sinopse da mesma maneira, apresentando-os praticamente como sinônimos, afirmando terem o resumo e a sinopse "a mesma caracterização ou função enunciativa, pois se trata de uma apresentação breve e concisa de um texto para dar ao leitor um apanhado geral do texto integral, é colocada entre este e o título" (COSTA, 2008, p. 166 apud SILVA; GOMES, 2011, p. 9). Nós, no entanto, consideramos resumo e sinopse dois gêneros distintos, uma vez que acreditamos ser a sinopse uma espécie de texto 'oficial', vinculado aos filmes ou livros, produzidos para serem inseridos no encarte da capa do filme (em DVD) e na contracapa do livro; já o resumo representa, para nós, uma síntese que pode ser produzida pelo público telespectador e leitor apresentando sua perspectiva a respeito da obra assistida/lida.

Sobre a sinopse de livro analisada aqui, podemos dizer que se trata de um gênero textual escrito, tendo como função enunciativa apresentar uma obra de literatura de ficção, de forma objetiva, clara, interessante e breve. Quanto aos três pilares que sustentam o gênero, destacamos que o conteúdo se refere à história presente no livro do qual se origina a sinopse; a estrutura composicional trata da organização do texto, se um ou mais parágrafos, trazendo principalmente uma visão geral do enredo, personagens principais e até trechos do próprio livro; e, por fim, o estilo diz respeito à "seleção dos recursos lexicais, fraseológicos e gramaticais da língua" (BAKHTIN, 2011, p. 261), 


\section{Revista do SELL}

v. 6 , no. 3

ISSN: $1983-3873$

lembrando que alguns gêneros, como os acadêmicos, por exemplo, não permitem uma maior aparição da individualidade de quem fala/escreve, embora a própria escolha de uma forma gramatical seja um ato individual (BAKHTIN. 2011, p. 269). A seguir, abordaremos o contexto em que foi produzida e revisada a sinopse.

\section{O CONTEXTO DE PRODUÇÃO/REVISÃO DA SINOPSE DO LIVRO}

A fim de conhecer a situação de produção da sinopse de livro aqui analisada, acreditamos ser importante realizar uma breve contextualização e algumas considerações.

$\mathrm{Na}$ ocasião em que foi produzida a sinopse do livro, o autor e o revisor já haviam trabalhado juntos na revisão do livro, que estava em processo de produção editorial, a fim de ser impresso e disponibilizado para lançamento. O livro $O$ manipulador de sonhos é uma obra de literatura ficcional, produzida por um jovem escritor baiano, e foi publicado em maio de 2015. Sua revisão foi realizada no final do segundo semestre de 2014. Já o texto-sinopse foi produzido e revisado em janeiro de 2015, tendo sido geradas três versões do mesmo texto: a primeira, produzida pelo autor; a segunda, revisada pelo profissional, e a terceira com novas inserções do revisor - destacamos que nas duas últimas ocorreu uma maior entrada do revisor na produção textual.

Nesse ínterim, ressaltamos alguns aspectos importantes que marcaram a produção do texto-sinopse que será apresentado em nossas análises:

- Autor e revisor tomaram o livro como ponto de partida para a produção da sinopse - o conhecimento do enredo;

- Enquanto o autor escreveu o livro, o revisor realizou, pelo menos, três leituras do texto completo, questionando e sugerindo ajustes. Portanto, os dois conheciam bem a obra da qual originou-se a sinopse;

- Na produção de textos em coautora, acreditamos que, quase sempre, um autor se sobressai mais que o outro ("o que segura a caneta/utiliza o computador"), contanto que os parceiros participem efetivamente, forneçam contribuições (TARGINO, 2005); 


\section{Revista do SELL}

v. 6 , no. 3

ISSN: $1983-3873$

- Na produção da sinopse, é possível perceber que os escreventes expõem suas perspectivas, suas observações, avaliações, diferentes visões sobre os fatos mais relevantes, sem fugir do enredo do livro;

- A produção do livro e a produção da sinopse marcam duas situações sociocomunicativas distintas.

Sendo assim, agora que apresentamos o contexto de produção da sinopse, abordaremos, na próxima seção, a noção de autoria com base em Bakhtin, Barthes, Foucault e Possenti, a fim de caracterizarmos essa entidade autoral e, dessa forma, discutirmos a possibilidade da coautoria, ocorrendo em concomitância à etapa de revisão textual.

\section{AUTORIA-REVISÃO-COAUTORIA: PROCESSOS ENVOLVIDOS NA PRODUÇÃO DE UMA SINOPSE DE LIVRO}

Definir autoria não é tarefa fácil, e não é o que buscaremos fazer aqui. Por isso, abordaremos relevantes considerações sobre a entidade autoral, a fim de refletir sobre ela, tendo em vista uma reflexão a respeito da possibilidade de coautoria na produção do gênero textual sinopse de livro, com destaque para o processo de revisão textual - etapa essencial na construção de um texto que apresenta uma obra.

A escrita da sinopse de livro objetiva apresentar brevemente o livro aos futuros leitores, dando uma dimensão objetiva e, ao mesmo tempo, interessante da estória contada. Assim como o próprio livro, do qual se originou a sinopse aqui analisada, que necessitou ser revisado, sendo esta uma das etapas do serviço editorial (YAMAZAKI, 2009), para ser apresentado ao público, a sinopse também foi submetida à revisão. Sobre este processo, consideramos, primeiro, que se trata de uma etapa da produção escrita (OLIVEIRA, 2016), além da releitura, correção, reescrita, retextualização etc.; segundo, não se baseia em pura correção gramatical, mas, de acordo com D'Andrea e Ribeiro (2010), em uma atividade que visa tornar o texto apresentável a um público, ou seja, a revisão de um texto implica contribuir com o objetivo daquele que escreve: comunicar-se de forma efetiva - sendo a efetividade a qualidade do "que produz efeito, que tem a capacidade de produzir o efeito desejado" (AULETE, 2017) -, a fim de produzir efeito(s) de sentido. 


\section{Revista do SELL}

v. 6 , no. 3

ISSN: $1983-3873$

Desse modo, partimos do pressuposto da Linguística textual que considera "o tratamento dos textos no seu contexto pragmático", no qual a "investigação se estende do texto ao contexto, este último entendido, de modo geral, como o conjunto de condições externas da produção, recepção e interpretação dos textos" (BENTES, 2001, p. 265). Assim, o sentido do texto não resulta apenas da 'vontade' de quem escreve, mas ele (o sentido) é construído por meio de interação, em uma dada situação sociocomunicativa (MARCUSCHI, 2008).

Ao tratar da revisão, revisores e pesquisadores costumam se referir, comumente, ao produtor do texto, àquele que escreve, como o autor/a autora. Mas, como se caracteriza esse autor? O que permite chamá-lo de autor? Quais pistas autorizam essa conceituação, a fim de supormos, também, a existência de uma coautoria? Seguindo nesta direção, propomos, então, discutir sobre a noção de autoria com base em Barthes, Foucault e Possenti, respectivamente, apresentando, assim, pistas que nos permitam supor uma coautoria na produção de uma sinopse de livro em processo/etapa de revisão. Antes, visitaremos a visão de Bakhtin (2011, p. 173), ao definir "o autor como participante do acontecimento artístico", uma vez que a sinopse, da qual tratamos, origina-se de uma obra literária.

Assim, conforme Cavalheiro (2008, p. 72, destaques da autora), Bakhtin alerta para a confusão feita entre "autor-criador, elemento da obra, e autor-pessoa, componente da vida". Para o autor russo, a autoria deve ser compreendida no acontecimento da obra, participando dela, na condição de "orientador autorizado do leitor" (BAKHTIN, 2011, p. 191), representando, para o leitor, "o conjunto de princípios criativos [...] vinculados à personagem e ao seu mundo". Portanto, é o autor o responsável pelo acabamento dado à personagem na atividade estética.

Em outro sentido, de acordo com Cavalheiro (2008, p. 68), fundando-se em Chartier (1999), antes do direito autoral ser reconhecido, as primeiras ações para estabelecer a identidade da autoria ocorreram na Idade Média; uma vez que alguns livros eram censurados, considerados heréticos, via-se a necessidade de assinatura dos mesmos, a fim de identificar e condenar os responsáveis por essa transgressão. Barthes, então, assinala que "o autor é uma personagem moderna, produzida sem dúvida pela nossa sociedade, na medida em que, ao terminar a Idade Média [...] ela descobriu o prestígio pessoal do indivíduo" (BARTHES, 1984, p. 49). 


\section{Revista do SELL}

v. 6 , no. 3

ISSN: $1983-3873$

Para Barthes (1984, p. 51), a Linguística contribui para a destruição do autor quando mostra que a enunciação é "um processo vazio que funciona na perfeição sem precisar ser preenchido pela pessoa dos interlocutores". Desse modo, quem fala é a própria linguagem, não o autor; assim, quando "o sujeito assume a linguagem, ele se constitui como algo que já está dado" (CAVALHEIRO, 2008, p. 71). Barthes (1984, p. 51) propõe o afastamento do autor, dando lugar ao escriptor, que "nasce ao mesmo tempo em que seu texto" (p. 52) e considera, ainda, que o "texto é um tecido de citações", originadas de várias culturas e que só podem fazer sentido em um único lugar: o leitor. Sendo assim, tanto o escritor quanto o leitor são produtores do texto, mas, para situar a escrita em seu lugar, propõe que "o nascimento do leitor tem de pagar-se com a morte do Autor" (BARTHES, 1984, p. 53).

Foucault, por sua vez, no ensaio O que é um autor?, apresenta o que seria uma resposta às considerações de Barthes a respeito do desaparecimento do autor. Para tanto, salienta seu desejo de se debruçar "tão só sobre a relação do texto com o autor, a maneira como o texto aponta para essa figura que the é exterior e interior, pelo menos em aparência" (FOUCAULT, 2002, p. 34). Nesse sentido, propõe que alguns discursos são providos da função autor, ou seja, o "modo de existência, de circulação e de funcionamento de alguns discursos no interior da sociedade" (FOUCAULT, 2002, p. 46); assim, o autor pode ser definido com base na relação com uma obra ou com uma discursividade - instauradores de discursividades, como Marx e Freud.

Dessa forma, conforme Foucault, a concepção de autor, de autoria, somente se aplicaria a indivíduos que tivessem uma obra em circulação ou que fossem fundadores de uma discursividade, apontando, assim, o seu funcionamento histórico na sociedade. Embora Foucault tenha fornecido importantes questões a serem investigadas, de acordo com Possenti, seu tratamento deixa em aberto (ou até mesmo apaga) "a questão da autoria quando se trata de outros espaços que não sejam os de uma obra ou de uma discursividade" (POSSENTI, 2001, p. 16-17), como no caso de textos de escolares, por exemplo, nos quais seria possível apontar indícios de autoria, pistas que apontam para uma tomada de posição, que é ideológica.

Possenti (2002), portanto, busca tratar da noção de autoria em textos que não representam, necessariamente, uma obra ou o estabelecimento de discursividade, propondo ser a autoria efeito de um estilo e de uma posição enunciativa. Assim, considera que um estudante não possui uma obra ou discursividade, o que poderia pôr fim à 


\section{Revista do SELL}

v. 6 , no. 3

ISSN: $1983-3873$

discussão, ou permitir a introdução de uma nova perspectiva - Possenti opta por esta segunda alternativa, apontando traços, indícios que apontam para o autor em outras esferas, "outros espaços que não sejam os de uma obra ou de uma discursividade", como propõe Foucault (POSSENTI, 2001, p. 17).

Antes de tudo, deixemos clara uma coisa: nós, aqui, não iremos analisar uma produção textual de um estudante, não se trata de um texto escolar, mas, sim, de um texto (sinopse de livro ficcional) produzido e revisado por indivíduos escolarizados em meio ao processo de editoração de um livro a ser publicado. Quando Possenti nos fala a respeito de apontar para a autoria em outros espaços, outras esferas, conforme dissemos acima, apesar de aplicar os indícios a textos escolares, vemos aberta a possibilidade desses mesmos critérios serem aplicados a uma sinopse, a uma resenha crítica, por exemplo, uma vez que se trata de gêneros que permitem uma maior aparição da singularidade de quem escreve.

Dessa forma, retomando as pistas de autoria, segundo as palavras de Possenti (2001):

quando se fala de autoria, pensa-se em alguma manifestação peculiar relacionada à escrita; em segundo lugar, não se pode imaginar que alguém seja autor, se seus textos não se inscreverem em discursos, ou seja, em domínios de 'memória' que façam sentido; por fim, creio que nem vale a pena tratar de autoria sem enfrentar o desafio de imaginar verdadeira a hipótese de uma certa pessoalidade, de alguma singularidade (POSSENTI, 2001 , p. 17, destaque do autor).

Sobre essa manifestação peculiar da escrita, vale ressaltar que não se trata simplesmente de obedecer às exigências de ordem gramatical, uma vez que um texto coeso nem sempre significa um texto coerente; no entanto, ressaltamos a importância, também, do aspecto gramatical no caso da sinopse, visto ser um texto de apresentação 'oficial' da obra, levado a público, sendo esse público letrado, atento às exigências gramaticais, uma vez que "a chamada língua padrão [que é ensinada pela escola] é de fato o dialeto dos grupos sociais mais favorecidos" (POSSENTI, 1996, p. 18) - o que representa um fator ideológico, uma característica do posicionamento do sujeito em determinado contexto, independentemente do extrato social a que pertence, pois tanto a norma considerada padrão como a não padrão representam possibilidades de manifestação do falante em contextos distintos. 


\section{Revista do SELL}

v. 6, no. 3

ISSN: $1983-3873$

Ainda conforme Possenti (2002), para que alguém se torne autor são necessárias as seguintes atitudes: que dê voz aos outros enunciadores e que mantenha distância em relação ao próprio texto; e destaca, ainda, a importância de se evitar a 'mesmice'. Pereira e Silva (2014), abordando os indícios de autoria em textos de escolares surdos, com base em Possenti (2002), destacam que "para se dar voz a outros discursos é necessário que o sujeito/autor se valha de recursos lexicais capazes de proporcionar uma avaliação do autor do discurso". Ademais, para manter a distância, o autor necessita saber se posicionar em seu texto, refletindo singularidade e originalidade, que apontem para intervenções que só podem ser realizadas por ele, e, no intuito de evitar a mesmice, Possenti afirma tratar-se de variar, "mas de variar segundo posições enunciativas, segundo a natureza do discurso. Trata- se de uma intervenção do sujeito, que não deixa para o leitor a tarefa de julgar se se trata de uma confissão, de uma admissão, etc." (POSSENTI, 2002, p. 120).

Portanto, estabelecidos os indícios que apontam para a autoria, podemos considerar que para que haja a ocorrência de coautoria seria necessário observar esses mesmos 'movimentos' por parte do coautor, ou seja, observar no texto produzido em coautoria as seguintes atitudes por parte dos indivíduos envolvidos: dar voz aos outros enunciadores, manter distância em relação ao próprio texto, evitar a mesmice, proporcionar uma avaliação do autor do discurso, saber se posicionar no processo de enunciação, sem deixar para o leitor a tarefa de julgar do que se trata em determinado texto.

Targino (2005, p. 9), ao tratar das mutações sofridas pelo processo de autoria, debruçando-se especialmente sobre a coautoria em artigos científicos, afirma que a coautoria "sempre existiu", e cita como exemplo de sua ocorrência a descoberta do DNA, em 1953, pelos cientistas Francis Crick e James Watson, marcando, desse modo, uma produção científica em parceria. Destaca, ainda, que a ocorrência de produção científica em coautoria ganhou força após a Segunda Guerra Mundial, alcançando seu ápice na sociedade pós-moderna, "com a possibilidade de integração e interação entre usuário e periódico, autor e leitor, tônica da esfera eletrônica" (TARGINO, 2005, p. 9). Targino aborda termos como trabalho em colaboração, elaboração em equipe, pesquisa em colaboração, produção em parceria, a fim de tratar da produção em coautoria; no caso da produção de artigos científicos, ressalta ser essa produção com mais de um autor condicionada por uma pressão social e profissional (publicação). 


\section{Revista do SELL \\ v. 6 , no. 3 \\ ISSN: $1983-3873$}

Porém, interessa-nos, aqui, corroborar a assertiva de que a coautoria "pressupõe, [...] no mínimo, a participação efetiva em todas as etapas de produção [textual], pelo menos na esfera dos impressos" (TARGINO, 2005, p. 11). Dessa forma, podemos supor que produzir um texto em coautoria significa participar de sua feitura, do projeto de escrita/dizer, do planejamento dos objetivos a serem alcançados, enfim participar das etapas de produção do texto até que seja apresentado ao(s) leitor(es), sendo a entrada/colaboração dos autores, no texto, significativa. Para tanto, assumimos o texto como um evento comunicativo no qual encontram-se imbricadas ações linguísticas, sociais e cognitivas, conforme Marcuschi (2008), citando Beaugrande (1997).

$\mathrm{Na}$ seção seguinte, apresentamos o texto sinopse de livro ficcional sob análise, a fim de apontar os indícios de autoria, fundando-nos em Possenti, e a possibilidade de coautoria no processo de produção/revisão da produção.

\section{COAUTORIA EM PROCESSO DE REVISÃO DE SINOPSE DE LIVRO - ANÁLISE}

Se considerarmos a autoria, de acordo com Foucault (2002), como correlata de uma obra que tenha circulação, poderemos dizer que o responsável pelo livro do qual se originou a sinopse é um autor, mesmo que não seja fundador de uma discursividade, pois ele possui uma obra publicada por uma editora e disponibilizada em livrarias. Podemos, ainda, nos apoiar em Bakhtin (2003, p. 11 apud CAVALHEIRO, 2008, p. 73), para quem "o autor-criador [...] é constituinte do objeto estético", sendo o responsável pelo acabamento da personagem.

Conforme dissemos, apresentamos, aqui, uma sinopse de livro ficcional submetida ao processo de revisão textual, na qual acreditamos que o revisor não apenas realizou intervenções de natureza linguístico-gramaticais no texto, mas, também, tornou-se coautor, uma vez que deixou no texto pistas que nos permitem percebê-lo ao mesmo tempo em que percebemos o autor do livro. Vejamos, a seguir, a primeira versão da sinopse, produzida pelo autor do livro e enviada ao revisor para ajustes linguísticogramaticais.

\footnotetext{
Allan, um jovem talentoso e ambicioso é o melhor aluno da cidade de Agosto, porém, todas as suas qualidades ficam em segundo plano devido a uma existência vazia e sem muitas expectativas. Um dia, sua vida sem perspectivas sofre uma mudança radical, ao encontrar um estranho garoto chamado Whisper: um manipulador de sonhos, capaz de controlar mentes, roubar sonhos e de transformar pensamentos em realidade. O mesmo aparece nos sonhos de
} 


\title{
Revista do SELL
}

v. 6 , no. 3

ISSN: $1983-3873$

\begin{abstract}
Allan com a proposta de torná-lo um humano perfeito, capaz de usar todo o potencial da mente. Ao aceitar a habilidade do estranho garoto, Allan começa a controlar e roubar mentes para incrementar na sua, mas ele também descobre que a mente guarda todos os segredos de seu detentor. Passado, presente e, sobretudo, o futuro pode ser refletido nos sonhos mais profundos, isso faz com que o manipulador possa ver o futuro daquele que é controlado. Com esta habilidade, Allan toma posse das mentes de grandes escritores e as desenvolvem, aperfeiçoando em seu próprio interior, para assim concretizar uma de suas maiores ambições: se tornar o melhor escritor de sua época.
\end{abstract}

Retomemos, portanto, as pistas apontadas por Possenti (2001, 2002), a fim de analisarmos, inicialmente, o texto apresentado pelo autor do livro, no intuito de apontar, brevemente, indícios de autoria no texto-sinopse em processo de produção, quais sejam: dar voz aos outros enunciadores, manter distância em relação ao próprio texto, evitar a mesmice, proporcionar uma avaliação do autor do discurso, saber se posicionar no processo de enunciação, sem deixar para o leitor a tarefa de julgar do que se trata em determinado texto. Quanto a dar voz aos outros enunciadores, o que implica incorporar outros discursos outros, destacamos que, ao produzir a sinopse, ela é construída com base no livro, de onde vêm as afirmações a respeito do personagem: "um jovem talentoso e ambicioso"; sobre manter a distância em relação ao próprio texto, caracterizado por Possenti (2002) como a marcação da posição do enunciador, por meio de uma postura avaliativa, destacamos o seguinte trecho: "Um dia, sua vida sem perspectivas sofre uma mudança radical" - vemos, neste trecho, a expressão do ponto de vista do enunciador em relação ao personagem, com base no fato de ele possuir "uma existência vazia". Por fim, em relação a evitar a mesmice, o que, de acordo com Possenti (2002), implica no como dar voz aos outros, o enunciador seleciona recursos, como os verbos "roubar [sonhos]", "controlar [sonhos e mentes]", promovendo efeitos de sentido que apenas ele, na condição de produtor do texto sinopse, poderia fazer, contribuindo, dessa forma, com o julgamento do leitor. Diante disso e com base no que propõe Possenti, podemos dizer que é possível, sim, identificar autoria no texto em questão - observável não no nível textual, mas discursivo.

Com base nessa versão, apresentada anteriormente, inicia-se o trabalho do revisor, o qual empreende uma leitura para compreensão, com a adição de avaliação (não sobre certo ou errado, mas como forma de estratégia), seguida da solução de possíveis problemas (OLIVEIRA, 2016) - fato semelhante ao que é apresentado por Passarelli (2012), em que um dos autores apresenta uma versão inicial, seguida de reescrita, revisão etc., pelo autor com quem escreve, conforme discutimos na introdução. Dessa 


\section{Revista do SELL \\ v. 6 , no. 3 \\ ISSN: $1983-3873$}

forma, após a revisão, foi produzida a segunda versão, encaminhada para o autor, a fim de apreciá-la, conforme a ilustração (Figura 1) que se segue:

Figura 1 - Segunda versão da sinopse de livro

\begin{tabular}{|c|c|}
\hline $\begin{array}{l}\text { Allan, um jovem talentoso e ambicioso, é o melhor e mais promissor aluno da cidade de } \\
\text { Agosto, porém, todas as suas qualidades ficamsão colocadas em segundo plano devido }\end{array}$ & A. $\begin{array}{l}\text { aIENIE } \\
\text { Concorda? Veja. }\end{array}$ \\
\hline $\begin{array}{l}\text { à sensação de possuir uma existência vazia e sem muitas expectativas. Um dia, sua } \\
\text { iida sem perspectivas sofre uma mudança radical; ao encontrar um estranho garoto }\end{array}$ & $\begin{array}{l}\text { QIENTE } \\
\text { O que acha de "vazia" em lugar de "perspectivas"? A palavra } \\
\text { está causando eco com "expectativas". Caso concorde, } \\
\text { suprima o "sem" anterior à palavira. }\end{array}$ \\
\hline $\begin{array}{l}\text { chamado Whisper: um manipulador de sonhos; capaz de controlar mentes, de roubar } \\
\text { sonhos e de transformar pensamentos em realidade. } 0 \text { mesmegaroto aparece nos sonhos } \\
\text { de Allan com a proposta de torná-lo um humano perfeito, capaz de usar todo o potencial } \\
\text { dade sua mente. Ao aceitar a habilidade deoferecida pelo estranho garoto, Allan começa }\end{array}$ & $\begin{array}{l}\text { QIIENIE } \\
\text { Oque acha de "conhecer" em lugar de "encontrar"? Veja. }\end{array}$ \\
\hline $\begin{array}{l}\text { a controlar e roubar mentes para incrementar na sua, mas ele também descobre que a } \\
\text { mente guarda todos os segredos de seu detentor. Assim, ppassado, presente e, } \\
\text { sobretudo, o futuro podem ser refletidos nos sonhos mais profundos, isso faz com } \\
\text { quepermiteao manipulador possa-ver o futuro daquele que é controlado. Com estsa }\end{array}$ & 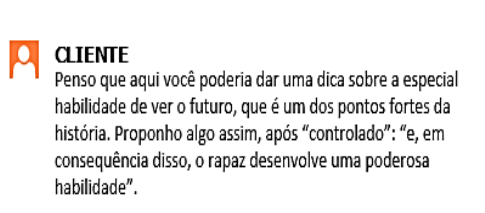 \\
\hline $\begin{array}{l}\text { habilidade, Allan toma posse das mentes de grandes escritores e as desenvolvem, } \\
\text { aperfeiçoando-as em seu próprio interior, para assim concretizar uma de suas maiores } \\
\text { ambições: se tornar o melhor escritor de sua épocae assim transformar as pessoas e o }\end{array}$ & $\begin{array}{l}\text { O. CUENTE } \\
\text { Seria importante salientar sobre esses escritores que "alguns } \\
\text { muito perigosos" eaqui dar o gancho para os } \\
\text { enfrentamentos, para suscitar um pouco da ação que há na } \\
\text { história durante os conflitos com os inimigos. Acho que seria } \\
\text { interessante. }\end{array}$ \\
\hline$\underline{\text { mundo a sua volta mediante suas palavras. }}$. & $\begin{array}{l}\text { OIENTE } \\
\text { Creio que seja importante salientar essa informação, pois é } \\
\text { um dos desejos do manipulador. Veja. Caso concorde, pode } \\
\text { reescrever conforme queira. }\end{array}$ \\
\hline
\end{tabular}

Fonte: Banco de dados das pesquisadoras.

A Figura 2, a seguir, apresenta um recorte - ampliação - dos comentários do revisor presentes na figura anterior, a fim de que possam ser melhor visualizados pelos leitores, uma vez que, em nossas discussões, damos destaque aos três últimos comentários. 


\section{Revista do SELL}

v. 6 , no. 3

ISSN: $1983-3873$

Figura 2 - Comentários da segunda versão da sinopse de livro

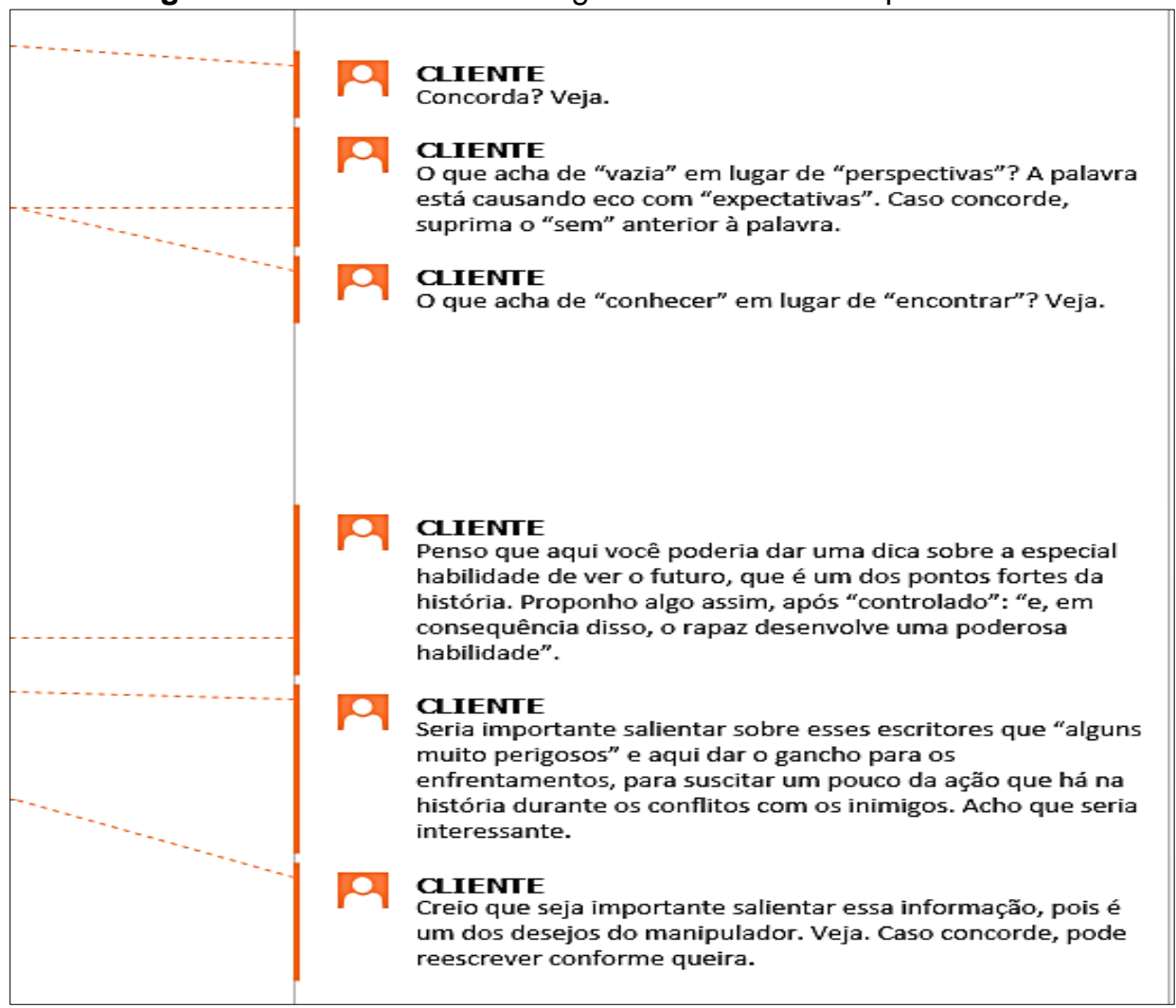

Fonte: Banco de dados das pesquisadoras.

A segunda versão nos permite notar, por meio da revisão indicativa (destaques no texto, em azul), inserções de palavras e até de trechos, como "e mais promissor", "sensação de possuir"; substituições, como na expressão "o mesmo", substituída por "o garoto"; reformulação de construções, como é o caso de "isso faz com que o garoto" para "isso permite ao garoto"; e, por meio da revisão interativa (balões/comentários à direita), propostas de substituições, reformulações e inserções de novas informações, como mostram os comentários [C4], [C5] e [C6]:

[C4] Penso que aqui você poderia dar uma dica sobre a especial habilidade de ver o futuro, que é um dos pontos fortes da história. Proponho algo assim, após "controlado": "e, em consequência disso, o rapaz desenvolve uma poderosa habilidade".

[C5] Seria importante salientar sobre esses escritores que "alguns muito perigosos" e aqui dar o gancho para os enfrentamentos, para suscitar um pouco da ação que há na história durante os conflitos com os inimigos. Acho que seria interessante.

[C6] Creio que seja importante salientar essa informação, pois é um dos desejos do manipulador. Veja. Caso concorde, pode reescrever conforme queira.

A partir das intervenções realizadas no texto inicial, podemos observar a entrada do revisor no texto, mediante estratégias que permitem o enriquecimento do texto. 


\section{Revista do SELL \\ v. 6 , no. 3 \\ ISSN: $1983-3873$}

Destacamos, ainda, que já nesses primeiros 'movimentos' realizados pelo revisor, supomos ser possível verificar o processo de coautoria, visto que o revisor também apresenta, em sua relação com o texto, pistas, indícios que demonstram sua presença autoral concomitante ao processo de revisão, sendo esta uma das etapas de produção do texto, até chegarem a uma versão final.

Assim sendo, verificamos que o revisor incorpora ao texto outros enunciados, principalmente advindos do livro, ao acrescentar, por exemplo, que o personagem, além de ser o melhor, também é o "mais promissor" aluno da localidade, ao inserir o trecho "e assim transformar as pessoas e mundo a sua volta mediante suas palavras" (dá voz aos outros enunciados). O revisor também marca sua posição enunciativa, mediante avaliação, denotada em suas escolhas, quando propõe no comentário cinco ([C5]) que: 'Seria importante salientar sobre esses escritores que 'alguns muito perigosos' e aqui dar o gancho para os enfrentamentos [...]", apresentando, desse modo, seu ponto de vista, aquilo que, para ele, chama atenção na estória do livro (mantém a distância em relação ao próprio texto) - isso, por sua vez, conduz ao que Possenti (2002, p. 119) propõe no sentido de "variar segundo posições enunciativas, segundo a natureza do discurso. Tratase de uma intervenção do sujeito, que não deixa para o leitor a tarefa de julgar" do que se trata determinado enunciado - representado no texto pela substituição do verbo "encontrar" por "conhecer [o garoto]", por exemplo (evita a mesmice).

Além disso, destacamos que a revisão da primeira versão não implica correção em aspecto gramatical, pois o texto encontra-se livre de tais problemas. Ademais, a segunda versão, revisada, foi encaminhada ao autor do livro, via E-mail, juntamente com uma mensagem (fornecida a nós pelo próprio revisor), conforme a Figura 3, a seguir, demonstrando 0 alto envolvimento do profissional com a produção da sinopse, em parceria com o autor do livro. De acordo com Targino (2005, p. 11), conforme dissemos anteriormente, a coautoria significa "a participação efetiva em todas as etapas de produção [textual], pelo menos na esfera dos impressos", sendo a efetividade a produção de um efeito desejado. 


\section{Revista do SELL}

v. 6 , no. 3

ISSN: $1983-3873$

Figura 3 - Mensagem do revisor para o autor do livro

Para @yahoo.com.br>
Eis o texto "sinopse do livro" e "sobre o autor". Como de costume, fiz algumas
alterações e sugestões, basicamente um diálogo que travo contigo a fim de aprimorar
sua proposta. Na minha opinião, está faltando "tocar" em alguns pontos fortes da
história, como o enfrentamento do mal, os confrontos, por exemplo. Mas podemos
debater sobre isso. Veja minhas propostas e faça os ajustes necessários. Aguardo
retorno. Um abraço!
|
P. S.: A construção da sinopse é mesmo muito importante, pois dará uma dimensão
objetiva da história.

Fonte: Banco de dados das pesquisadoras.

Destacamos da mensagem de E-mail os seguintes trechos: "[...] Na minha opinião, está faltando 'tocar' em alguns pontos fortes da história, como o enfrentamento do mal, os confrontos, por exemplo. Mas podemos debater sobre isso. [...] P. S.: A construção da sinopse é mesmo muito importante, pois dará uma dimensão objetiva da história". Diante disso, é possível verificar que o revisor se posiciona em relação à versão revisada por ele, da qual participa, acreditando possuir, ainda, lacunas a serem preenchidas. De acordo com o revisor, após o envio desse E-mail, o autor do livro solicitou que o ajudasse a 'enriquecer' a sinopse, pois temia não despertar o interesse de seus leitores.

Dessa forma, após apreciação do texto pelo autor da obra (que concordou com as sugestões), e reenviou ao revisor, foi produzida uma nova versão do texto, para conferência: a terceira versão, como mostra a Figura 4, a seguir. Nessa nova versão, o revisor, ao qual consideramos coautor na produção da sinopse, além de incluir os trechos propostos na versão anterior, produziu o trecho final, ocupando as últimas três linhas do texto (destacados em vermelho). 


\title{
Revista do SELL
}

v. 6 , no. 3

ISSN: $1983-3873$

Figura 4 - Terceira versão da sinopse de livro

\begin{abstract}
Allan, um jovem talentoso e ambicioso, é o melhor e mais promissor aluno da cidade de Agosto, porém todas as suas qualidades são colocadas em segundo plano devido à sensação de possuir uma existência vazia e sem muitas expectativas. Um dia, sua vida vazia sofre uma mudança radical ao conhecer um estranho garoto chamado Whisper: um manipulador de sonhos capaz de controlar mentes, de roubar sonhos e de transformar pensamentos em realidade. $O$ garoto aparece nos sonhos de Allan com a proposta de torná-lo um humano perfeito, capaz de usar todo o potencial de sua mente. Ao aceitar a habilidade oferecida pelo estranho garoto, Allan começa a controlar e roubar mentes para incrementar a sua, mas ele também descobre que a mente guarda todos os segredos de sen detentor. Assim, passado, presente e, sobretudo, o futuro podem ser refletidos nos sonhos mais profundos, isso permite ao manipulador ver o futuro daquele que é controlado-e.em conseguência disso o rapaz desenvolve nma poderosa habilidade. Com essa habilidade, Allan toma posse das mentes de grandes escritores, alguns muito perigosos, e as desenvolve, aperfeiçoandoas em seu próprio interior, para assim concretizar uma de suas maiores ambiçòes: se tornar - melhor escritor de sua época e assim transformar as pessoas e o mundo a sua volta mediante suas palavras., que também podem controlar todos aqueles que as seguirem. Em meio a um turbilhão de acontecimentos, o iovem toma conhecimento de segredos e mistérios que vão além de sua existência.
\end{abstract}

Fonte: Banco de dados das pesquisadoras.

Nesta versão, após ajuste das propostas anteriores do revisor, em todo o texto, foi dado destaque apenas para os trechos sugeridos e formulados pelo revisor, com destaque para a parte final do texto, conforme dissemos, onde insere um período um pouco maior: [...] que também podem controlar todos aqueles que as seguirem. Em meio a um turbilhão de acontecimentos, o jovem toma conhecimento de segredos e mistérios que vão além de sua existência".

Novamente, e com base apenas neste trecho final da sinopse, podemos verificar a presença dos indícios de autoria apontados por Possenti $(2001,2002)$ nesse processo de produção em parceria (TARGINO, 2005), ou seja, o coautor da sinopse, fundado em seu conhecimento da obra, uma vez que a leu pelo menos três vezes durante o processo de revisão, incorpora ao texto-sinopse o discurso presente na história, dando voz a esse discurso; mantém distância em relação ao próprio texto, ao marcar "sua posição em 


\section{Revista do SELL}

v. 6 , no. 3

ISSN: $1983-3873$

relação ao que dizem e em relação a seus interlocutores" (POSSENTI, 2002, 114), expressando seu ponto de vista, por meio da avaliação dos acontecimentos presentes na estória, chamando-os de "turbilhão de acontecimentos". O que leva, necessariamente, ao abandono da mesmice, ao variar na seleção de recursos que contribuem com o julgamento do leitor; neste caso, a seleção do vocábulo "seguirem" referindo-se às palavras do manipulador, produzindo efeitos como "acreditarem", "obedecerem" às suas palavras, por exemplo.

A seguir, na conclusão, apresentamos, nossas considerações a respeito do que nos propomos a investigar: se na etapa de revisão textual de uma sinopse, com a entrada do revisor no texto produzido pelo autor do livro que deu origem à sinopse, houve a ocorrência de coautoria.

\section{CONCLUSÃO}

Discutimos, aqui, a respeito da autoria, tomando por base os pressupostos teóricos de Bakhtin (autor-criador), Barthes (a morte do autor), Foucault (função autor) e Possenti (indícios de autoria), a fim de podermos melhor compreender e caracterizar essa figura e, desse modo, propor a presença de autoria em uma sinopse de livro de ficção, mas, principalmente, a ocorrência de coautoria nesse mesmo texto, com destaque para a etapa de revisão textual à qual a sinopse foi submetida durante sua escrita.

Da produção da sinopse participaram o escritor do livro que deu origem à sinopse e o revisor - tanto do livro quanto da sinopse. Dessa forma, foi apresentada uma primeira versão do texto ao revisor que, por sua vez, realizou interferências, ajustes e propostas, além de fazer algumas sugestões, sendo solicitado pelo escritor da obra a ajudá-lo a tornar o texto mais atraente, ocorrendo, então, num contexto interativo de produção, discussões e ações sobre o texto. Essa 'entrada' do revisor no texto representa movimentos que vão além da revisão, se a considerarmos uma espécie de intervenção no texto do outro, no intuito de contribuir para sua apresentação a um público.

Com base em Possenti, ao propor indícios, pistas, marcas que apontam para a autoria em outros espaços, outras esferas, diferente da relação com uma obra ou fundação de discursividade, conforme Foucault, como em textos escolares, por exemplo, consideramos o contexto de feitura da sinopse um outro espaço de produção do texto, no qual pode aparecer a singularidade de quem escreve; logo, podendo aparecer, também, 


\section{Revista do SELL \\ v. 6 , no. 3 \\ ISSN: $1983-3873$}

uma presença coautoral, uma vez que a coautoria representa um fenômeno já observado em nossa sociedade, especialmente entre a comunidade científica. Consideramos, portanto, a coautoria como uma produção em parceria, em que os parceiros fornecem importantes contribuições.

Quanto aos indícios de autoria, quais sejam: dar voz aos outros enunciados, manter a distância em relação ao próprio texto e evitar a mesmice de acordo com Possenti, acreditamos tê-los demonstrado na primeira versão da sinopse produzida pelo escritor do livro, sendo este a primeira entidade autoral identificada nesse processo de escrita. Do mesmo modo, em relação ao revisor, embora tenha partido de uma primeira versão, o que não é incomum, pois, na escrita em parceria, um acaba escrevendo mais que o outro, porém com contribuições igualmente importantes, vimos o revisor incorporar a entidade autoral, ao passo que acrescenta à sinopse informações do livro (o "mais promissor" aluno da localidade), dando voz aos outros enunciados; marca sua posição enunciativa, mediante avaliação, por meio de suas escolhas, quando propõe no comentário cinco que "Seria importante salientar sobre esses escritores que 'alguns muito perigosos' e aqui dar o gancho para os enfrentamentos [...]", e, assim, mantém a distância em relação ao próprio texto, variando segundo as posições enunciativas; além de evitar a mesmice, mediante as escolhas que faz (substituição do verbo "encontrar" por "conhecer [o garoto]").

Portanto, consideramos que na produção da sinopse de livro de ficção, em processo de revisão textual, aqui analisada, houve, sim, a ocorrência do fenômeno de escrita em coautoria, pois os movimentos realizados pelo revisor, no texto, à luz dos indícios apontados por Possenti, são da mesma ordem dos movimentos realizados pelo escritor do livro, aprimorando a sinopse por meio da interação estabelecida entre eles.

\section{REFERÊNCIAS}

AULETE DIGITAL. Dicionário Caldas Aulete. Disponível em: <http://www.aulete.com.br/efetivo>. Acesso em: 15 abr. 2017.

BAKHTIN, Mikhail Mikhailovitch. Estética da criação verbal. Prefácio à edição francesa Tzvetan Todorov; introdução e tradução do russo Paulo Bezerra. - 6ª ed. - São Paulo: Editora WMF Martins Fontes, 2011.

BARTHES, Roland. A morte do autor. In: BARTHES, Roland. 0 rumor da língua. Tradução de António Gonçalves. Lisboa: Edições 70, 1984, p. 49-53. 


\section{Revista do SELL}

v. 6 , no. 3

ISSN: $1983-3873$

BENTES, Anna Christina. Linguística Textual. In: Introdução à Linguística: domínios e fronteiras, v. 1/ Fernanda Mussalim, Anna Christina Bentes (orgs.). São Paulo: Cortez, 2001, p. 245-282.

CAVALHEIRO, Juciane dos Santos. A concepção de autor em Bakhtin, Barthes e Foucault. Signum: Estud. Ling., Londrina, no 11/2, p. 67-81, dez. 2008. Disponível em: <http://www.uel.br/revistas/uel/index.php/signum/article/viewFile/3042/2585>. Acesso em: 15 abr. 2017.

D' ANDREA, C. F. B.; RIBEIRO, A. E. Retextualizar e reescrever, editar e revisar: Reflexões sobre a produção de textos e as redes de produção editorial. Revista Veredas on line - atemática - 1/2010, p. 64-74 - PPG Linguística/UFJF (ISSN 1982-2243). Disponível em: < http://www.ufjf.br/revistaveredas/files/2010/08/ARTIGO-5.pdf >. Acesso em: 10 abr. 2017.

FOUCAULT, Michel. O que é um Autor? Coleção Passagens, Vega, Lisboa, 2002.

MARCUSCHI, Luiz Antônio. Produção textual, análise de gêneros e compreensão. São Paulo: Parábola Editorial, 2008. 296p.: - (Educação linguística; 2)

PASSARELLI, Lílian Ghiuro. Ensino e correção na produção de textos escolares. São Paulo: Cortez, 2012.

POSSENTI, Sírio. Por que (não) ensinar gramática na escola. Campinas, SP: Mercado de Letras: Associação de Leitura do Brasil, 1996. (Coleção Leituras no Brasil)

POSSENTI, Sírio. Enunciação, autoria e estilo. Revista da FAEEBA / Universidade do Estado da Bahia, Departamento de Educação. Salvador, no 15, p. 15-21, jan./jun., 2001. Disponível em: <http://www.uneb.br/revistadafaeeba/files/2011/05/numero15.pdf>. Acesso em: 19 abr. 2017.

POSSENTI, Sírio. Indícios de autoria. Perspectiva, Florianópolis, 1-20, n. 01, p. 105-24, jan./jun. 2002. Disponível em:

<https://periodicos.ufsc.br/index.php/perspectiva/article/viewFile/10411/9677>. Acesso em: 20 abr. 2017.

SILVA, Josenir Sousa da; GOMES, Rosivaldo. O ensino do gênero textual resumo/sinopse de filme por meio de sequência didática. Revista Práticas de Linguagem. v. 1, n. 2, jul./dez. 2011. Disponível em: <http://www.ufjf.br/praticasdelinguagem/files/2012/02/Relato-1-O-ensino-dog\%C3\%AAnero-textual-resumo-sinopse-de-filme-por-meio-de-Sequ\%C3\%AAnciaDid\%C3\%A1tica.pdf>. Acesso em: 18 abr. 2017.

TARGINO, Maria das Graças. Artigos científicos: a saga da autoria e co-autoria. Intercom - Sociedade Brasileira de Estudos Interdisciplinares da Comunicação. XXVIII Congresso Brasileiro de Ciências da Comunicação - Uerj - 5 a 9 de setembro de 2005. Disponível em: <http://www.intercom.org.br/papers/nacionais/2005/resumos/R0277-1.pdf>. Acesso em: 26 abr. 2017. 


\section{Revista do SELL}

v. 6 , no. 3

ISSN: $1983-3873$

YAMAZAKI, C. Edição de texto na produção editorial de livros: distinções e definições. [2009] 231f. Dissertação de Mestrado (Ciências da Comunicação) - Universidade de São Paulo, SP, 2009. Disponível em:

<file:///G:/Textos\%20sobre\%20revisão/Edição\%20de\%20textos\%20Cristina\%20Yamazaki .pdf>. Acesso em: 16 abr. 2017. 